\title{
Water vapour distribution at urban scale using high-resolution numerical weather model and spaceborne SAR interferometric data
}

\author{
E. Pichelli ${ }^{1}$, R. Ferretti ${ }^{1}$, D. Cimini ${ }^{1}$, D. Perissin ${ }^{2}$, M. Montopoli ${ }^{1,4}$, F. S. Marzano ${ }^{1,3}$, and N. Pierdicca ${ }^{3}$ \\ ${ }^{1}$ Department Physics, University of L'Aquila/CETEMPS, L'Aquila, Italy \\ ${ }^{2}$ Institute of Space and Earth Information Science, Chinese University of Hong Kong, Hong Kong, China \\ ${ }^{3}$ Department Electronic Engineering, Sapienza University of Rome, Rome, Italy \\ ${ }^{4}$ Department of Electrical and Information Engineering, University of L'Aquila, L'Aquila, Italy
}

Received: 12 May 2009 - Revised: 19 November 2009 - Accepted: 7 December 2009 - Published: 22 January 2010

\begin{abstract}
The local distribution of water vapour in the urban area of Rome has been studied using both a high resolution mesoscale model (MM5) and Earth Remote Sensing-1 (ERS-1) satellite radar data. Interferometric Synthetic Aperture Radar (InSAR) techniques, after the removal of all other geometric effects, estimate excess path length variation between two different SAR acquisitions (Atmospheric Phase Screen: APS). APS are strictly related to the variations of the water vapour content along the radar line of sight. To the aim of assessing the MM5 ability to reproduce the gross features of the Integrated Water Vapour (IWV) spatial distribution, as a first step ECMWF IWV has been used as benchmark against which the high resolution MM5 model and InSAR APS maps have been compared. As a following step, the high resolution IWV MM5 maps have been compared with both InSAR and surface meteorological data. The results show that the high resolution IWV model maps compare well with the InSAR ones. Support to this finding is obtained by semivariogram analysis that clearly shows good agreement beside from a model bias.
\end{abstract}

\section{Introduction}

Water vapour is one of the most important constituents of the atmosphere because its phase changes are responsible for clouds and precipitation, whose interaction with electromagnetic radiation is a crucial factor in atmospheric system regulation. Despite of its importance within atmospheric processes over a wide range of spatial and temporal scales, water vapour is one of the least understood and poorly described components of the atmosphere. It is very difficult to observe

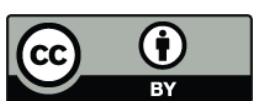

Correspondence to: E. Pichelli (emanuela.pichelli@aquila.infn.it) water vapour variations over its wide range of spatial and temporal scales. The complex topography of the Mediterranean area causes a large spatial variability of the water vapour, often turning on severe weather (Rotunno and Ferretti, 2001, 2003). Moreover, at the local scale, water vapour may also vary because of the local circulation (Ferretti et al., $2003 \mathrm{~b}$ ) producing fast temporal variations. A review by Collier (2006) about the impact of the urban area on the weather clearly shows the importance of observations in understanding these influences, but strongly highlights the deficiencies of our knowledge of the physical and dynamical processes at the local scale. The recent development of high resolution weather forecast models helps in understanding the central role of water vapour in correctly reproducing all scales flow.

Currently the high spatial resolution Numerical Weather Prediction (NWP) models are able to reproduce realistic water vapour distribution fields, but their limiting factor is the poor resolution of the initial conditions. The lack of both precise and continuous water vapour data is one of the major sources of error in short-term forecast of precipitation (Kuo et al., 1993, 1996). An improvement in monitoring the atmospheric water vapour and its assimilation in NWP models would lead to more accurate forecasts of precipitation and severe weather. In this context, benefits from InSAR high resolution phase delay can be fully employed if ground motion and topography effects are effectively isolated from water vapour contribution to the signal delay.

On the other hand, from the point of view of SAR interferometric applications (e.g. the analysis of progressive tectonic motions, or to the improvement of a Digital Terrain Model), unwanted contributions on the received signal induced by the atmosphere are big sources of noise for InSAR techniques, especially at $\mathrm{C}$ and $\mathrm{X}$ frequency bands. Among them, the delay caused by changes in the distribution of water vapour in the atmosphere (Foster, 2006). By analyzing single interferograms, the water vapour delay contribution is practically

Published by Copernicus Publications on behalf of the European Geosciences Union. 


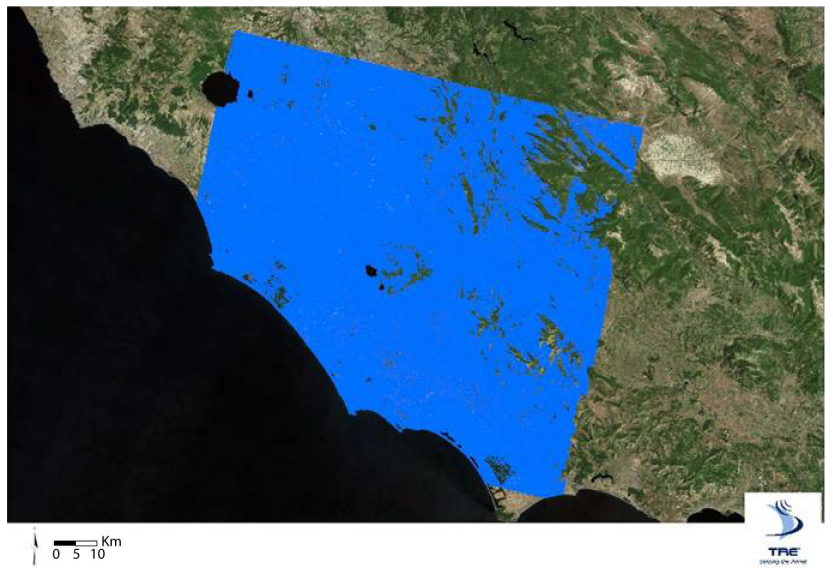

Fig. 1. PS distribution. The $100 \times 100 \mathrm{~km}^{2}$ blue area contains approximately $2806 \times 103$ PS.

indistinguishable from ground motion signal: its amplitudes can range from some millimetre up to several centimetres or even greater. This leads to a real difficulty in detecting ground deformation events. Large efforts have been spent to solve this problem (Webley et al., 2002), by developing methods to mitigate water vapour error by reconstructing the most likely atmospheric scenario. The most known techniques use observations, such as soundings, Global Positioning System (GPS) receiver networks, ground or space based radiometers: the last ones generally exhibit poor temporal or spatial resolution. Satellite-based radiometers accuracy may strongly depend on the surface (land/water) over which the measurements are acquired (Webley et al., 2002). Water vapour field produced by a high resolution NWP, can provide a good support to solve some of these problems. Indeed, high resolution meteorological models can be used to calculate atmospheric delay to be subtracted from InSAR interferograms, to reduce noise on the geodetic signals.

In this study the InSAR data are used for the first time over the urban area of Rome combined with a high resolution numerical forecast model, producing a completely new approach for studying/verifying circulation and thermodynamics of urban areas; preliminary results of the investigation of the high resolution water vapour field are here presented. The version 3 of Mesoscale Model 5 (MM5) (Dudhia, 1993) is used to produce high resolution water vapour fields to be compared with InSAR data, which have been processed with the Permanent Scatterers (PS) technique (Ferretti et al., 2001).

\section{InSAR data processing}

The PS technique exploits long series of SAR data to estimate ground motion and relative height of a sparse set of points (PSs) that are coherently imaged in the whole dataset, isolating in this way the tropospheric differential de- lay, called Atmospheric Phase Screen (APS). This study has been carried out using data acquired during the three-day repetition phase of ERS1 in 1994, when there was a satellite overpass over the same area every three days (Ferretti et al., 2003a). The density and quality of the detected PSs obtained with so frequent satellite passages is impressive (Fig. 1), resulting in a very high spatial density of APS of about one every $100 \mathrm{~m}^{1}$. Thus, the APS can be converted into integrated water vapour $\left(\mathrm{IWV}^{2}\right)$ and compared with MM5.

In this analysis, the integrated water vapour provided by MM5 is compared with the APS one retrieved with the PS technique. Information about the difference in IWV between two acquisitions, called hereafter the differential IWV ( $d \mathrm{IWV}$ ), can be retrieved from SAR data as follows.

The atmospheric refractivity introduces bending and slowing along the propagation path of the SAR microwave signal (Davis et al., 1985). The observed signal delay can be interpreted as the result of various atmospheric delay contributions (Hanssen et al., 1999). In the clear atmosphere the delay consists of the ionospheric, hydrostatic and wet components; if aerosols and hydrometeors (such as dust, clouds, and rain) are present, an additional contribution has to be considered. The ionospheric and hydrostatic components give large contribution but they are quite homogeneous within a typical SAR frame, thus, they are easily computed and removed (Hanssen et al., 1999). Aerosols and hydrometeors, instead, have a smaller contribution $(\sim 0.1-1.0 \mathrm{~mm})$ unless heavy rain is detected (Solheim et al., 1999). Therefore, the wet component, i.e. the contribution from atmospheric water vapour, is the most relevant for SAR applications, due also to its high spatial and temporal variability.

Following Onn and Zebker (2006), the total phase shift in the radar interferogram, caused by propagation through the neutral atmosphere, is modelled as:

$$
\begin{aligned}
\Delta \Phi & =\Delta \Phi(x, y, t)-\Delta \Phi\left(x, y, t_{0}\right) \\
& =\frac{4 \pi}{\lambda \cos \theta}\left[\Delta l(x, y, t)-\Delta l\left(x, y, t_{0}\right)\right],
\end{aligned}
$$

where $t$ indicates time and $t_{0}$ is the time of a reference acquisition (master); $\boldsymbol{r}=[x, y, z]^{T}$ is the position vector, with $z$ indicating the altitude with respect to the Earth's surface; $\theta$ is the local incident angle at the centre of the InSAR 100$\mathrm{km}$ wide swath (nominally at $23^{\circ}$ incidence angle); $\lambda$ is the free-space wavelength $(5.67 \mathrm{~cm}$ for ERS-1). If $N(\boldsymbol{r}, t)$ is the

\footnotetext{
${ }^{1}$ APS dataset was derived by re-sampling a dense PS set on a $100 \times 100 \mathrm{~km}^{2}$ area; considering the PS distribution almost uniform, it results on average a density of more than $350 \mathrm{PS} / \mathrm{km}^{2}$.

${ }^{2}$ The integrated water vapour is defined as the liquidequivalent columnar integrated vapour content calculated as follows: IWV $=\frac{1}{\rho_{\mathrm{L}}} \int \rho_{\mathrm{V}} d h$, where $\rho_{\mathrm{L}}$ is the liquid water density, $\rho_{\mathrm{V}}$ is water vapour volumetric density and $\mathrm{dh}$ is the vertical increment.
} 
wet component of the 3-D time-varying neutral atmospheric refractivity, then

$\Delta l(x, y, t)=10^{-6} \int_{0}^{\infty} N(\boldsymbol{r}, t) d z$

is the one-way excess path length in the zenith direction at the time $t$ due to propagation through the atmosphere up to a point $(x, y, 0)$, sometimes called Zenith Wet Delay (ZWD).

Therefore, the excess path length difference between acquisition times in the zenith direction is related to the measured total phase shift as:

$\Delta l(x, y)=\frac{\lambda \cos \theta}{4 \pi} \Delta \Phi(x, y)$

Note that the $\cos \theta$ factor maps delays in the slant direction to zenith; for incident angles typical of SAR observations $\left(23^{\circ}\right)$, this simple mapping function accurately projects slant delays to vertical and thus is commonly used (Hanssen et al., 1999; Onn and Zebker, 2006; Foster et al., 2006). Finally, assuming that the above excess path length is entirely due to atmospheric water vapour, the differential IWV is obtained introducing the conversion factor $\Pi$ (Davis et al., 1985):

$d \operatorname{IWV}(x, y)=\Pi \Delta l(x, y)=\Pi \frac{\lambda \cos \theta}{4 \pi} \Delta \Phi(x, y)$.

The conversion factor $\Pi$, widely used in GPS meteorology, is not a constant but rather a function of the weighted mean temperature of the atmosphere. However, the conversion factor can be estimated accurately and it shows little variability in a typical SAR frame. A typical value for $\Pi$ is six; therefore $6 \mathrm{~mm}$ of ZWD is equivalent to approximately $1 \mathrm{~mm}$ of IWV.

The $d$ IWV retrieved from SAR are calculated with respect to a reference radar overpass (master image): 5 March 1994. Note that the positive sign of the delay indicates that the feature appears in the first of the two combined SAR images.

\section{Weather model processing}

The fifth generation NCAR (National Center for Atmospheric Research) and Pennsylvania State University (PSU) mesoscale model MM5 is used for this study; this is a non hydrostatic model at primitive equations with a terrain following vertical coordinate and multiple nesting capabilities (Dudhia, 1993).

Four two-way nested domains are used (Fig. 2) to enhance the resolution over the urban area of Rome. The mother domain covers most of western Mediterranean area; it is centred at $41.5^{\circ} \mathrm{N}, 10.0^{\circ} \mathrm{E}$ and it has a spatial resolution of $27 \mathrm{~km}$. The nested domains cover Central Italy from a spatial resolution of $9 \mathrm{~km}$, for domain 2 , to $1 \mathrm{~km}$ for the inner one; this last encompasses the city area and its surroundings (Lazio region), greatly overlapping the ERS satellite swath.

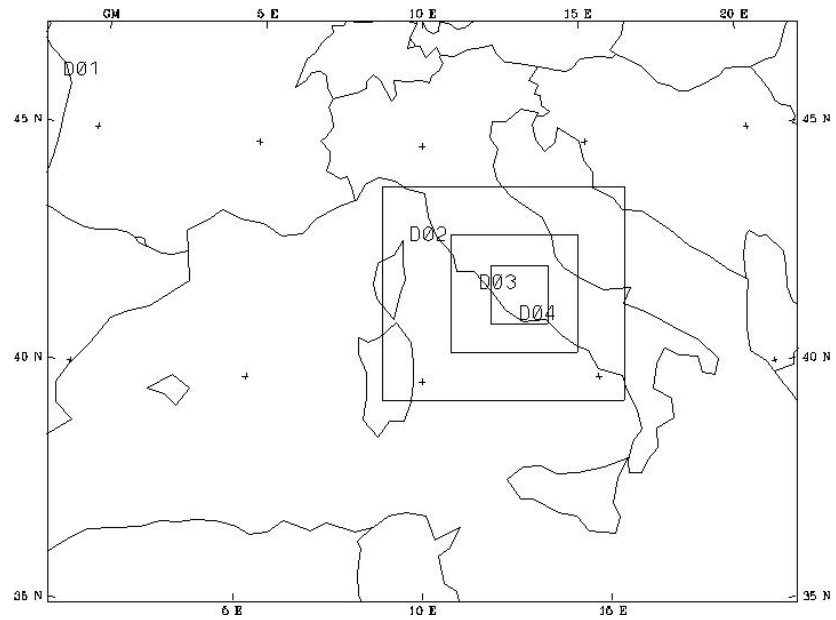

Fig. 2. MM5 domains configuration. Domain D1 has resolution of $27 \mathrm{~km}$; D2 has resolution of $9 \mathrm{~km}$; D3 has resolution of $3 \mathrm{~km}$; D4 has resolution of $1 \mathrm{~km}$.

Sensitivity tests and previous studies (Ferretti et al., 2003b; Ferretti and Raffaele, 2009) allowed for tailoring the optimal combination of physical parameterizations for the numerical experiments. Therefore, the following model configuration has been used:

- 33 unequally spaced vertical levels, from the surface up to $100 \mathrm{hPa}$, with a higher resolution in the planetary boundary layer (PBL);

- the MRF scheme for the PBL. This scheme is based on Troen-Mahrt representation of counter-gradient term and the eddy viscosity profile in the well mixed PBL (Hong and Pan, 1996);

- the CLOUD radiation scheme for radiative transfer processes. This scheme accounts for both shortwave and longwave interactions with explicit cloud and clear air (Stephens, 1984);

- the Kain-Fritsch 2 cumulus convection parameterization is applied to domains 1, 2 (Kain and Fritsch, 1993; Kain, 2004); whereas no cumulus scheme is used for domains 3 and 4;

- the Reisner 2 scheme for microphysics; based on mixedphase scheme, graupel and ice number concentration prediction equations (Reisner et al., 1998).

All the numerical experiments last $24 \mathrm{~h}$, from 00:00 UTC to 24:00 UTC for each chosen event. The European Centre for Medium-Range Weather Forecast (ECMWF) analysis for temperature, wind speed, relative humidity, and geopotential height at $0.25^{\circ}$ resolution are interpolated to the MM5 horizontal grid and to vertical levels to produce the model initial and boundary conditions. 

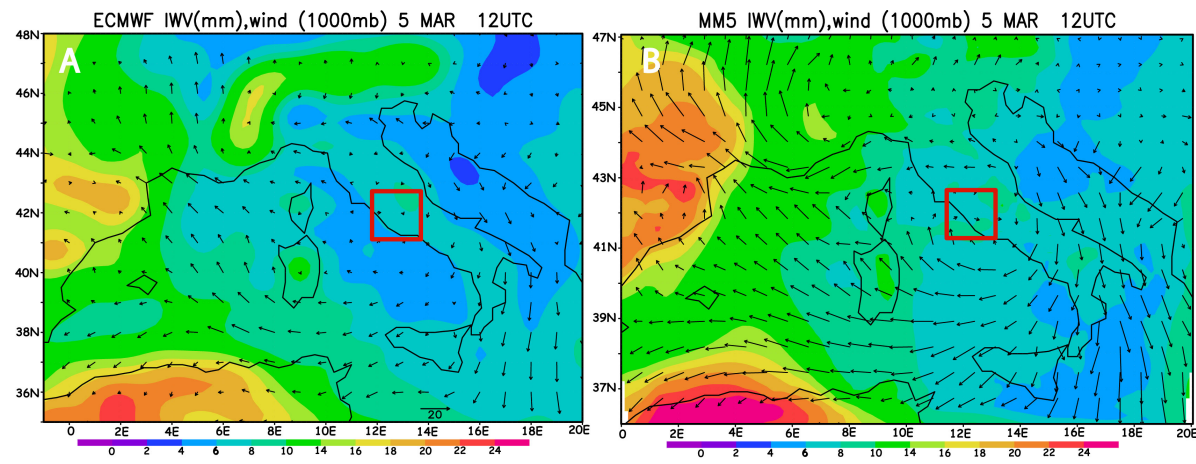

Fig. 3. 5 March 1994 at 12:00 UTC (master day): integrated water vapour by ECMWF (panel A) and MM5 on mother domain (panel B). The red square on each panel represents the area of high resolution (domain 4).

During 1994, several satellite passages in a relatively short period (from January to April) are available over the area of interest; among them a few cases have been simulated by MM5. In the next paragraph four cases will be presented: 31 January, 3 and 12 February, and 8 March.

\subsection{Results}

The MM5 2-way nesting capability allows for feeding back high resolution fields on the overlapping coarser domains. This clearly appears by the comparison between the MM5 mother domain simulation and ECMWF analysis. This comparison is performed to the aim of assessing MM5 improvements to the meteorological fields and eventually the accuracy of such correction. On the other hand, an evaluation of MM5 high resolution water vapour field will be performed using InSAR data of differential integrated water vapour respect to the master one (5 March 1994, Fig. 3), for each day. The results of this comparison will also evaluate the accuracy of the correction on the low resolution domains.

\subsubsection{MM5 versus ECMWF and InSAR}

\section{January 1994}

The comparison between MM5 and ECMWF IWV fields shows that the former produces a more humid field than the last one (Fig. 4, panels A and B) for 31 January. Both maps are referred to 12:00 UTC, which means $12 \mathrm{~h}$ after the MM5 start time. At coarse resolution the IWV clearly shows two maxima for ECMWF (Fig. 4, panel A): one over Central Italy eastern side, and the other one over the Balkans area. Similarly, MM5 develops two maxima, but displaced westward with respect to ECMWF (Fig. 4, panel A). This is probably caused by a weak or absent eastward wind component turning in a delay in the eastward migration of the two IWV maxima, as the evolution of the weather system in the following hours suggests (not shown). This hypothesis is supported by the north-westerly wind produced by MM5 along the western coast of Italy (Fig. 4, panel B) at low levels, and the north-easterly wind at $850 \mathrm{hPa}$ (not shown) on the north east side of Italy. The differential IWV shows lower values for MM5 than ECMWF, on domain 4 (Fig. 4, panels C and D, red square). Moreover, a reversed structure of high-low values along the diagonal of the red square ("diagonal structure" hereafter) is produced by MM5 with respect to ECMWF (Fig. 4, panels A and D). To further investigate the MM5 ability in producing high resolution water vapour, a comparison with InSAR data on the same area (Fig. 5) is carried out at the same time of ERS overpass. It has to be pointed out that MM5 maximum resolution is lower $(1 \mathrm{~km})$ than InSAR APS map resolution (about $100 \mathrm{~m}$ ). Moreover, because of the low reliability of InSAR data over sea, they cannot be used for the comparison in that area. The main features of the InSAR APS map are well reproduced by MM5 (Fig. 5), as well as the values range measured by the radar on 31 January at 10:00 $\mathrm{UTC}^{3}$ with respect to the master image. From these maps (Fig. 5), the influence of the topography on the IWV variations clearly appears for both MM5 and the radar data. Indeed, the minimum values in both cases are located over the hills nearby Rome and the western slope of Apennines (Fig. 5, light green to yellow areas). The InSAR (Fig. 5, right panel) shows the same diagonal structure aligned NWSE highlighted on low resolution maps, with high values in the north-west area and low ones in the south-east. MM5 reproduces this structure even if $d \mathrm{IWV}$ is overestimated in the south-east area (Fig. 5, left panel). The analysis of IWV fields, produced by MM5 at the following time steps (not shown), suggests a delay of about one hour in reproducing the observed structure.

The role of high spatial resolution can also be inferred by the comparison of ECMWF $d$ IWV with InSAR data: the low-high values structure along the diagonal are reversed in

\footnotetext{
${ }^{3}$ The comparison between MM5 and InSAR data are performed at 10:00 UTC, that is $2 \mathrm{~h}$ before the one presented at low resolution; this time difference in the comparison is due to the availability of ECMWF analysis only at 00:00, 06:00, 12:00 and 18:00 UTC. ERS overpass is at 10:00 UTC.
} 

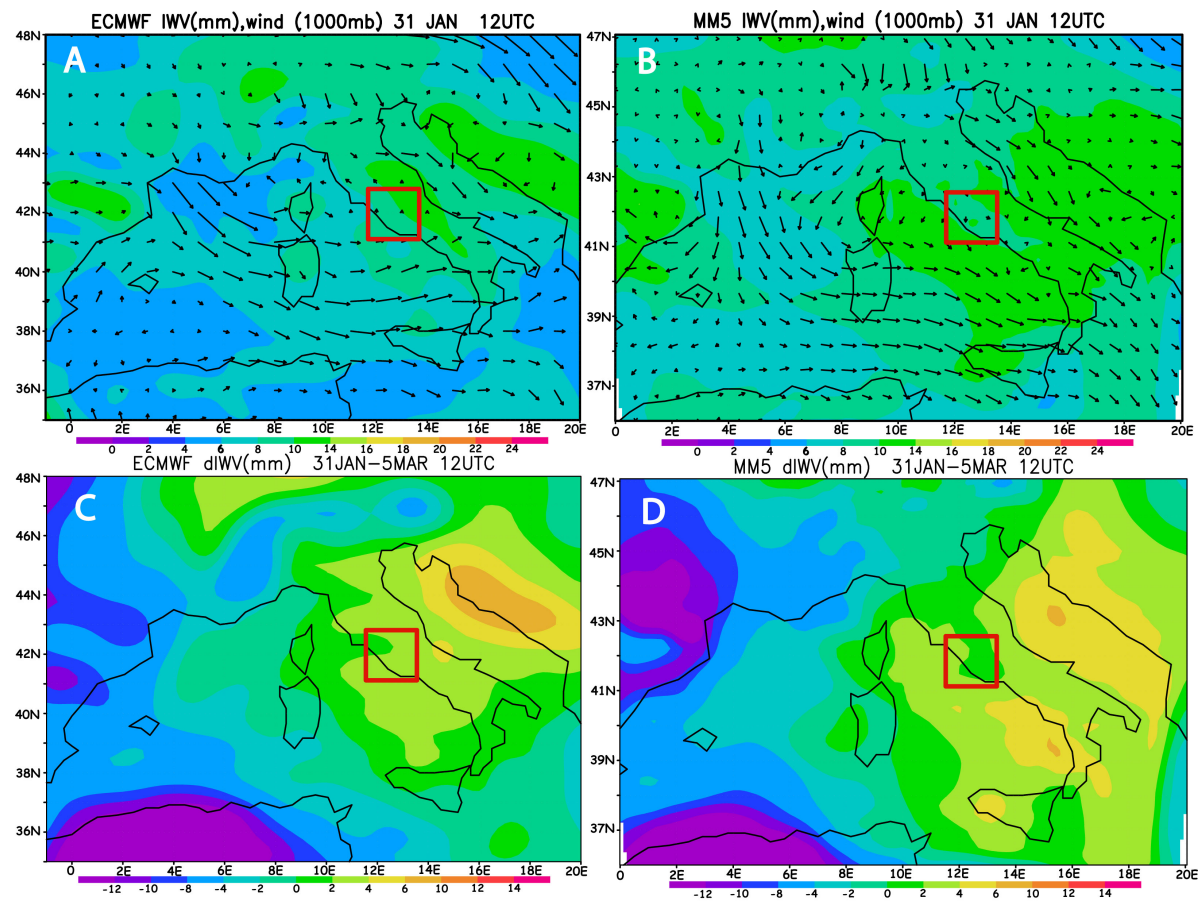

Fig. 4. 31 January 1994 at 12:00 UTC: integrated water vapour by ECMWF (panel A) and MM5 on mother domain (panel B); differential IWV respect to the master day (5 March) by ECMWF (panel C) and MM5 (panel D). The red square on each panel represents the area of high resolution (domain 4).
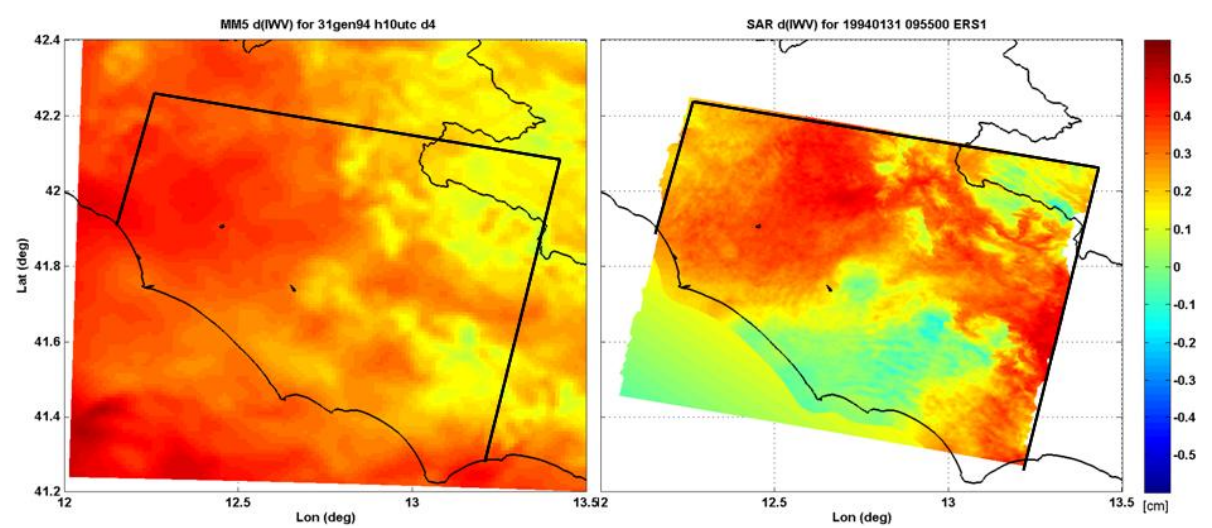

Fig. 5. [31 January-5 March] 1994 at 10:00 UTC: differential integrated water vapour ( $d$ IWV) produced by MM5 on high resolution domain (left panel) and measured by InSAR (right panel).

the ECMWF analysis (Fig. 4, panel C) with respect to InSAR map (Fig. 5, right panel). Of course, the MM5 $d$ IWV is produced by both the day under exam (31 January) water vapour field and the master day one; therefore, the exactness of the final differential field depends on the accuracy of both simulations. The IWV for the master day (5 March) produced by MM5 on domain 4 (red square in Fig. 3, panel B) shows a dipole structure (low-high) that can be related to the one previously discussed, whereas a homogeneous distribution of IWV is produced by MM5 for 31 January (Fig. 4, panel B). This suggests that the master day field is driving the differen- tial result in this case. On the other hand, ECMWF IWV does not show any dipole structure (low-high) nor for the master day (Fig. 3, panel A) or for 31 January (Fig. 4, panel A).

\section{February 1994}

The meteorology of the second case (3 February) is driven by a low pressure centred on west Europe (Fig. 6) that causes a southern flow over Mediterranean basin advecting humid air over Italy. Both ECMWF and MM5 produce this meteorological structure (not shown). However, the IWV field is 

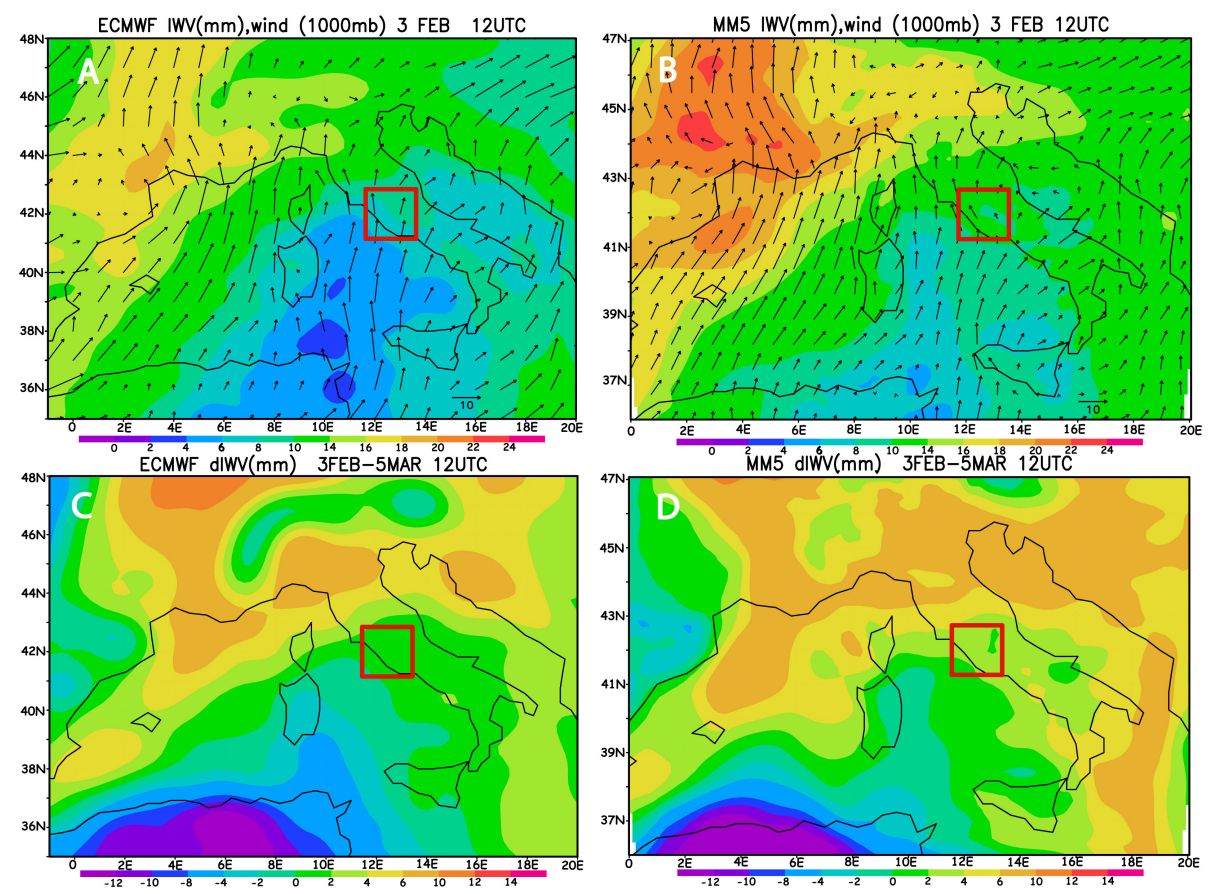

Fig. 6. 3 February 1994 at 12:00 UTC: integrated water vapour by ECMWF (panel A) and MM5 on mother domain (panel B); differential IWV respect to the master day (5 March) by ECMWF (panel C) and MM5 (panel D). The red square on each panel represents the area of high resolution (domain 4).

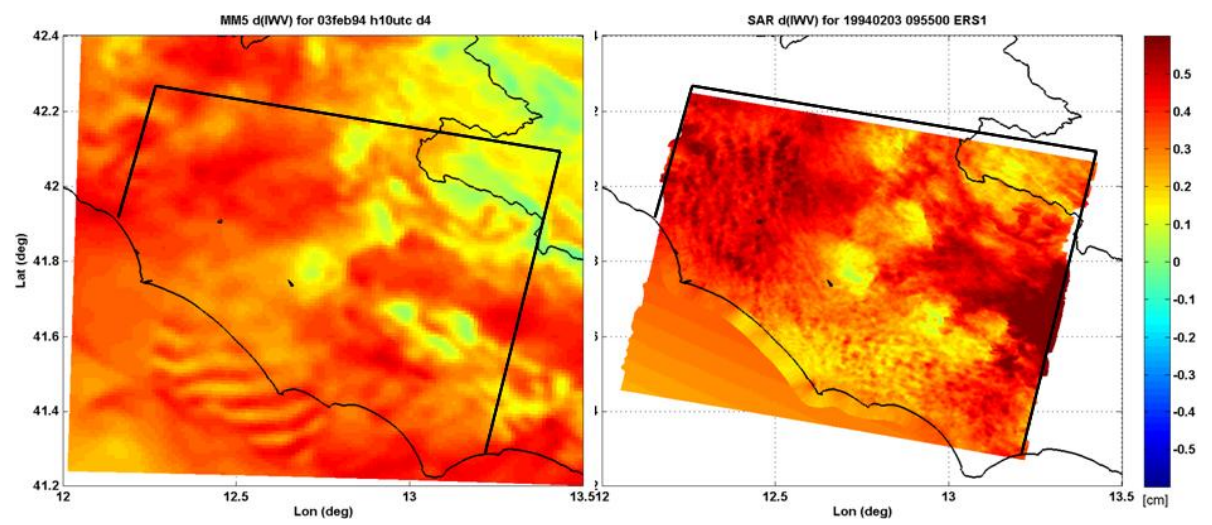

Fig. 7. [3 February-5 March] 1994 at 10:00 UTC: differential integrated water vapour ( $d$ IWV) produced by MM5 on high resolution domain (left panel) and measured by InSAR (right panel).

different for the two models: the MM5 IWV along the coast of Lazio is higher than the ECMWF one, but a tongue of lower IWV (Fig. 6, panel B) is rapidly approaching this region. This is caused by the wind veering eastward at upper levels, which turns in dryer air advection. On the other hand, ECMWF analysis shows (Fig. 6, panel A) a homogeneous field over the Tyrrhenian Sea and the IWV minimum is located south west. This produces a difference of IWV from 2 to $4 \mathrm{~mm}$ between MM5 and ECMWF on domain 4 area. The comparison between MM5 and InSAR data (Fig. 7) suggests that the model well reproduces the gross features of dIWV, even though it underestimates the maxima (approximately $1 \mathrm{~mm}$ ) and overestimates the minima. As expected, the high resolution features measured by the InSAR data are missed by MM5. Moreover, InSAR data clearly show a northwestsoutheast gradient of $d \mathrm{IWV}$ with higher values in the northwest corner than in the south (Fig. 7, right panel, respectively red to black area for the high values and orange to yellow for the low values). This would infer a reduction of IWV in the south side, if we suppose the master day having a homogeneous field. Unfortunately, we do not have any information on the high resolution IWV unless we assume as "true" the 

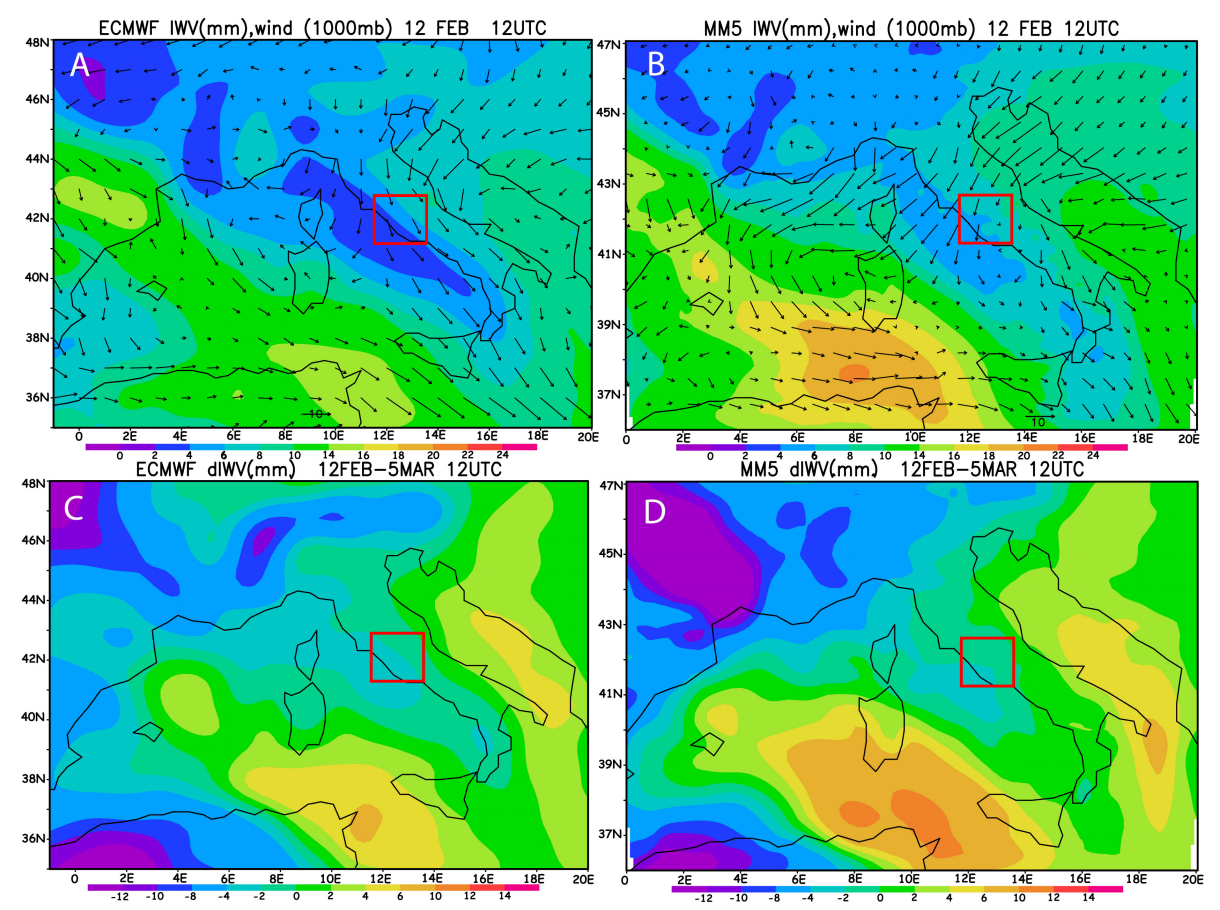

Fig. 8. 12 February 1994 at 12:00 UTC: integrated water vapour by ECMWF (panel A) and MM5 on mother domain (panel B); differential IWV respect to the master day (5 March) by ECMWF (panel C) and MM5 (panel D). The red square on each panel represents the area of high resolution (domain 4).

one produced by MM5. Following this assumption, high values of IWV are produced by MM5 in the southeast side (not shown) making the homogenous field hypothesis unrealistic, whereas the hypothesis of the master day driving the northsouth gradient is more suitable. Therefore, the IWV gradient is not correctly reproduced by MM5 at the time of the InSAR overpass. The low values of MM5 IWV at 12:00 UTC in the southwest corner of the box (not shown) would suggest a delay in the onset of the tongue of low IWV values, as already shown by the large scale structure (Fig. 6, panel B). On the other hand, ECMWF correctly produces a lower IWV in the inner domain (Fig. 6, panel A), but it completely misses the north-east gradient. The ECMWF IWV differences between 3 February and the master day are lower than MM5 ones; this would suggest that the differences between ECMWF and InSAR would be higher for positive values than MM5 ones. On the other hand, a better estimate of $d \mathrm{IWV}$ minima would be achieved by ECMWF in any event.

\section{February 1994}

The MM5 low resolution IWV is generally more humid than ECMWF analysis (Fig. 8, panels A and B) on 12 February. A strong north-easterly wind is produced by MM5 causing dry air over most of central Italy, whereas ECMWF is characterized by a north-westerly wind in the same area. In both cases, the area enclosed by domain 4 is characterized by very low values of integrated water vapour. The corresponding dif- ferential fields for ECMWF and MM5 (Fig. 8, panels C and $\mathrm{D}$, respectively) show similar results: both produce negative IWV values, but MM5 restrains them on south-west angle of the red square area. The IWV negative values imply that the master day is more humid than 12 February; this suggests that the master day drives the differential field, also in this case. Beside from an underestimation of the positive values and an overestimation of the negative ones, a good agreement is found between the MM5 high resolution $d \mathrm{IWV}$ and the satellite (Fig. 9). Moreover, the negative $d$ IWV values produced by MM5 are restrained in the south-east corner of the domain, covering a smaller area than the one measured by the InSAR (Fig. 9). Also in this case a time delay of the low $d \mathrm{IWV}$ entering the area can be hypothesized for MM5, but a concurring factor can obviously be introduced by the master day field structure. Indeed, the IWV for 5 March (Fig. 3, panel B) would suggest that yet the master day is driving the $d \mathrm{IWV}$ field for 12 February case, producing a tongue of high IWV values in the south-west area of the inner domain. Moreover, it can be inferred that larger discrepancies on this local structure would be produced by a low resolution field like the ECMWF one (Fig. 3, panel A), that shows an almost flat and low IWV field on the Lazio hinterland.

\section{March 1994}

Finally, a case (8 March 1994) producing large discrepancies between MM5 and InSAR is presented. The MM5 IWV 


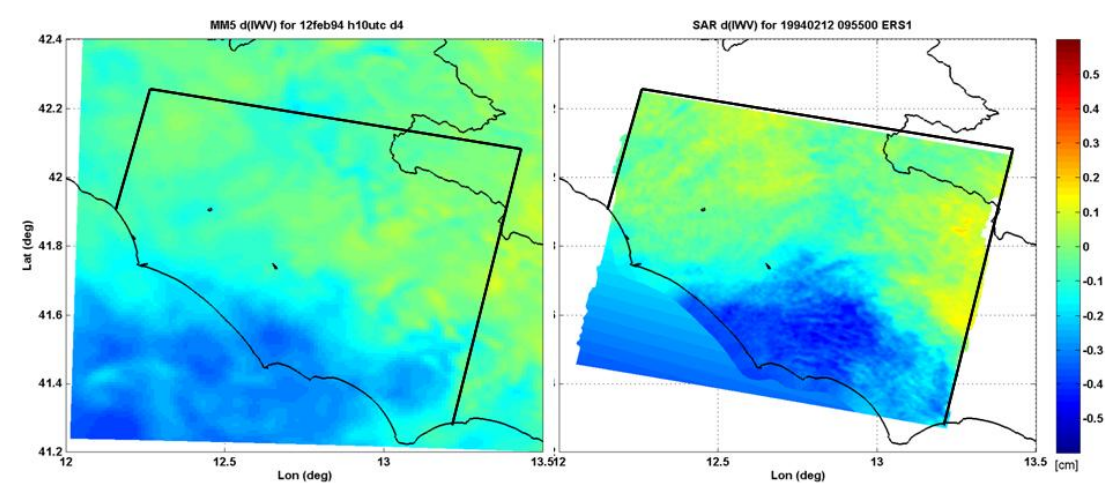

Fig. 9. [12 February-5 March] 1994 at 10:00 UTC: differential integrated water vapour (dIWV) produced by MM5 on high resolution domain (left panel) and measured by InSAR (right panel).

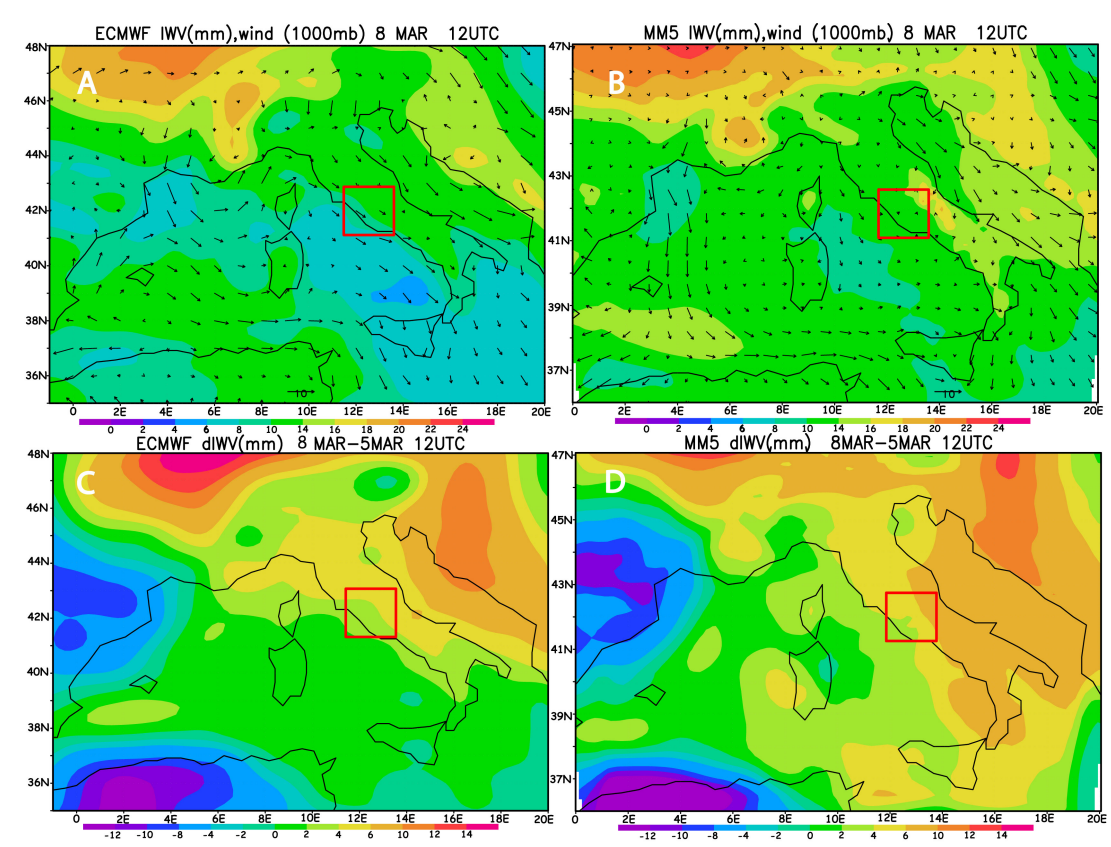

Fig. 10. 8 March 1994 at 12:00 UTC: integrated water vapour by ECMWF (panel A) and MM5 on mother domain (panel B); differential IWV respect to the master day (5 March) by ECMWF (panel C) and MM5 (panel D). The red square on each panel represents the area of high resolution (domain 4).

is generally more humid than the ECMWF one (Fig. 10, panels $\mathrm{A}$ and $\mathrm{B}$ ) over the whole domain and the horizontal MM5 wind field is weaker than the ECMWF one over the Italian peninsula. Also in this case a time delay in the large scale structure entering from north-west produced by MM5 (not shown) may cause these differences. The MM5 $d$ IWV field (Fig. 10, panels $\mathrm{C}$ and $\mathrm{D}$ ) is always positive and larger than ECMWF, over domain 4. The comparison between MM5 high resolution and the radar data shows large differences (Fig. 11): an almost completely homogeneous and positive field is produced by MM5 (Fig. 11, left panel), whereas a large northwest-southeast gradient is observed by the satellite (Fig. 11, right panel). MM5 overestimates In-
SAR data of approximately $2 \mathrm{~mm}$ in the north-west side and of more than $8 \mathrm{~mm}$ in the south-east side. The large scale field can help understanding these discrepancies. As already pointed out, the low resolution MM5 field (Fig. 10, panel B), clearly shows a generally overestimation of IWV over the Mediterranean basin, with a surplus of IWV over Central Italy. This is probably caused by a too weak eastward advection that inhibits the eastward migration of the minimum of IWV located over the Tyrrhenian Sea (Fig. 10, panel D). The entrance of the low IWV would have decreased water vapour content and consequently the differences respect to master day. The time delay caused by the too weak eastward advection previously hypothesized is, actually, confirmed by 


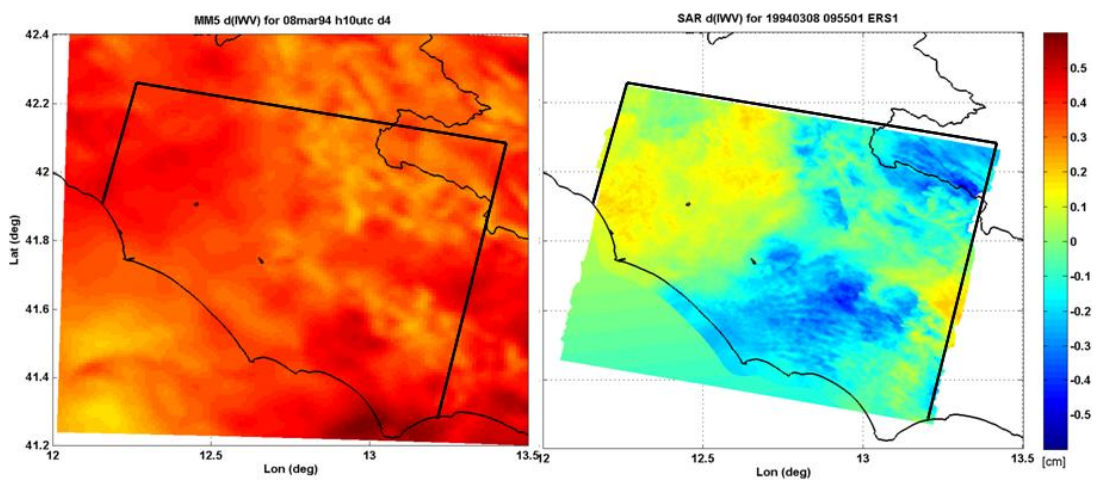

Fig. 11. [8-5 March] 1994 at 10:00 UTC: differential integrated water vapour ( $d$ IWV) produced by MM5 on high resolution domain (left panel) and measured by InSAR (right panel).

a good agreement between the $d$ IWV by InSAR and the one produced by MM5 more than two hours later (not shown).

This analysis clearly highlights differences between MM5 and ECMWF and a tendency of MM5 to over predict the wet field on coarser domain. Actually, a high resolution NWP is tailored for correctly reproducing the meteorological field at the high resolution, therefore the previous comparison between the MM5 low resolution and ECMWF is obviously highly penalising for MM5. The two models major discrepancies can be related to differences in the dynamics caused by both the different algorithms for the dynamics and parameterizations for the physics. Moreover, the feed back mechanism of the two-way nesting used by MM5 is not implemented in ECMWF: the two-way nesting capability allows the model to transfer high resolved information to mother domains and to capture features that can be missed on ECMWF low resolution. In the next paragraph, a comparison with upper air sounding will show that at lower levels MM5 does not show a clear signal in over or under estimating water vapour fields, but an overall good agreement with observations is found.

\subsubsection{MM5 versus upper air soundings}

An additional comparison between MM5 and both soundings data and surface stations (not shown) has been performed, to the aim of better evaluating the MM5 water vapour field. The scatter plots for temperature (Fig. 12, panel A), water vapour mixing ratio (Fig. 12, panel B), potential temperature (Fig. 12, panel C) and equivalent potential temperature (Fig. 12, panel D) produced by MM5 versus the soundings launched at Pratica di Mare $\left(41.65^{\circ} \mathrm{N}, 12.63^{\circ} \mathrm{E}\right.$, a station along the coast nearby Rome) at 12:00 UTC for all cases previously analyzed are shown. A general good agreement between MM5 and the real atmospheric profiles is obtained, beside of discrepancies in the PBL as the large spread at high temperature and water vapour content would suggest. The spread at the lower levels is expected because of the well known difficulties in correctly reproducing the PBL structure for MM5 (Dandou et al., 2005; Ferretti and Raffaele, 2009), especially at high resolution. Generally, the four MM5 variables infer a weak tendency of MM5 to underestimate the thermodynamic conditions of the atmosphere, except for the water vapour mixing ratio that shows (Fig. 12, panel B) a large uncertainty and a tendency to either over or under estimate the sounding values. Again, this is expected because of the larger water vapour content in the lower layer of the atmosphere.

\subsubsection{Semivariograms analysis}

In order to quantify the spatial characteristics of the IWV fields, MM5 simulations and InSAR observations have been compared in term of semivariogram. This is defined as the half average of the square differences between couples of values of integrated water vapour sampled at different lag distances; it produces a description of the spatial correlation of the handled fields. In addition, semivariograms are directly exploitable within kriging procedures for data integration purpose (e.g. to blend MM5 simulations, GPS and radiometers observations of integrated water vapour) which may be a valuable approach to mitigate water vapour effects for InSAR data exploitation.

The comparison between the semivariograms by MM5 and InSAR observations from ERS-1 platform suggests that MM5 well reproduces the spatial structure of integrated water vapour (Fig. 13, respectively grey and black lines). This can be inferred by the similarity in shape of the two semivariograms (MM5 and ERS1). For 3 February (Fig. 13), this is especially true at all scales, whereas for the other cases it is true only at small scales (below $5 \mathrm{~km}$ ). On the other hand, the comparison between the asymptotic behaviour at large spatial scales of the MM5 semivariogram and those originating from SAR infers a weaker ability in describing the variance of the integrated water vapour by MM5 (the grey curves of Fig. 13, at high lag distances underestimates the dark ones), except for 3 February being the one with the best variance agreement. Another important information deriving 

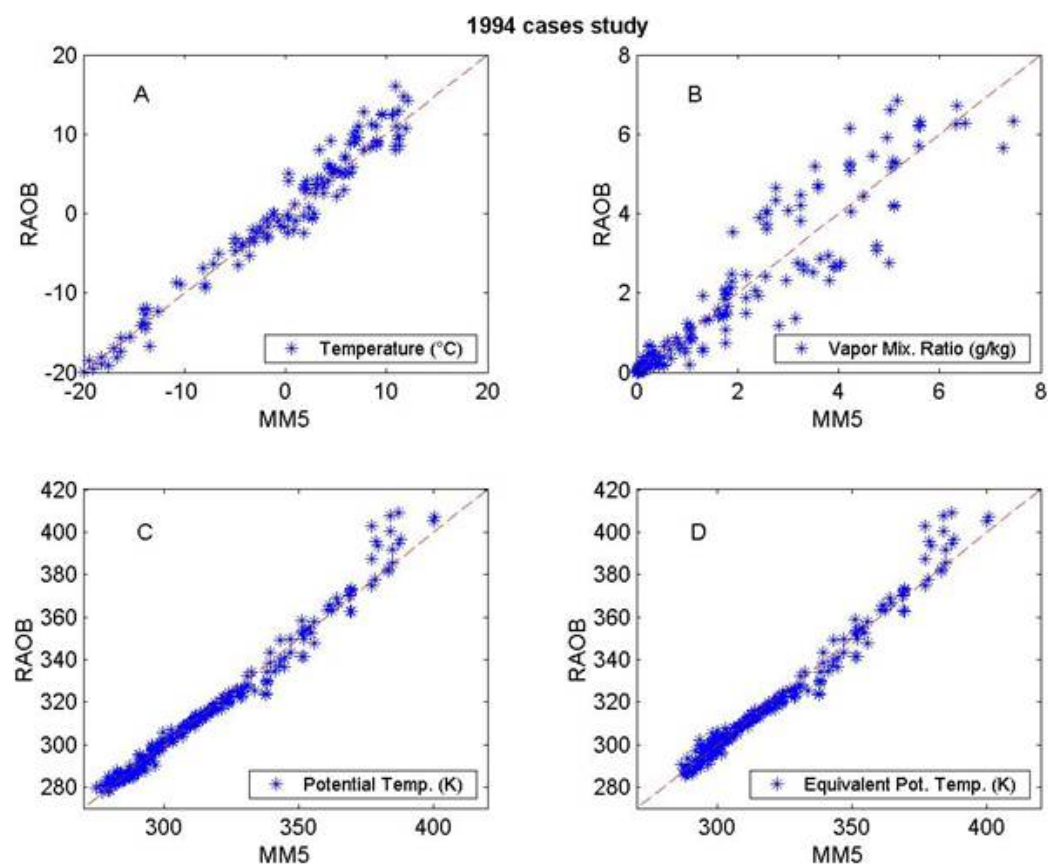

Fig. 12. Scatter plots between radiosondes launched at Pratica di Mare $\left(41.65^{\circ} \mathrm{N}, 12.63^{\circ} \mathrm{E}\right)$ site and MM5 at same coordinates. Different panels show: temperature $(\mathbf{A})$, vapour mixing ratio $(\mathbf{B})$, potential temperature $(\mathbf{C})$, equivalent potential temperature $(\mathbf{D})$. Data are referred to the four 1994 cases presented on this paper. Points are referred to different heights.
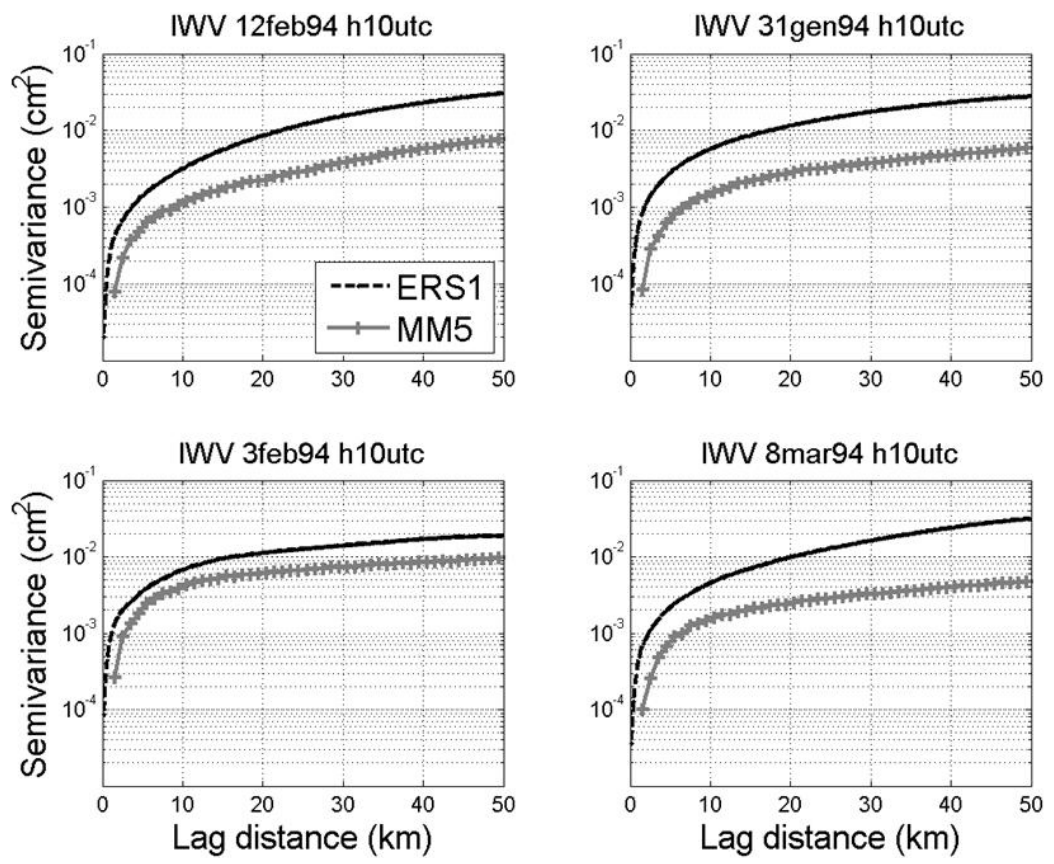

Fig. 13. Semivariograms of MM5 simulations (grey lines) and ERS 1 observations (black lines).

from semivariograms is the rate at which they reach the maximum (Fig. 14): gently increasing curves support a more spatially correlated water vapour field, in spite of curves rapidly reaching their plateau. The semivariograms produced by the
MM5 simulations increase at a smaller rate than those associated to InSAR measurements, with the exception of 3 and 12 February 1994 (Figs. 13-14). 

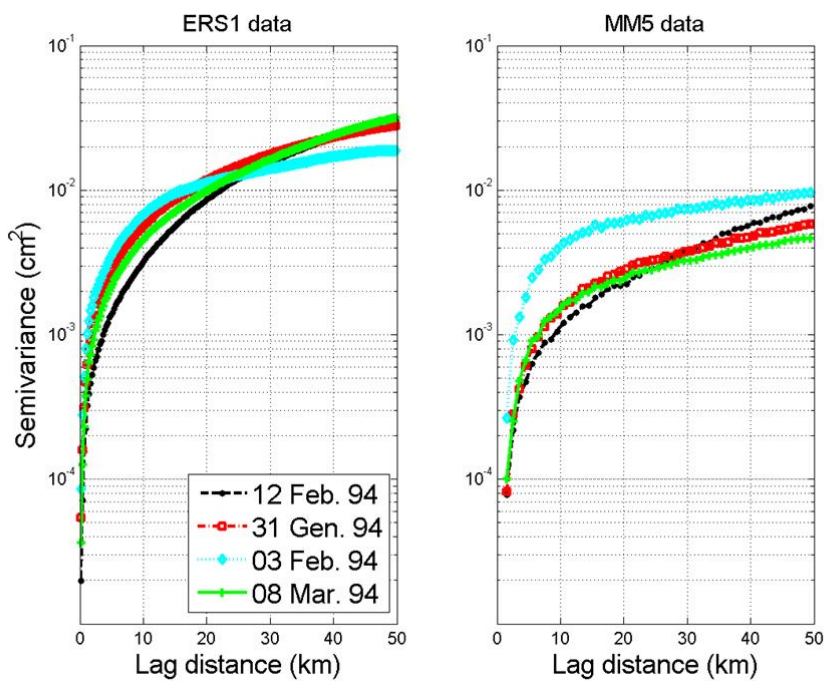

Fig. 14. Semivariograms of ERS 1 observations (left panel) and MM5 simulations (right panel) for the four cases study during 1994: 31 January, red line; 3 February, cyan line; 12 February, black line; 8 March, green line.

Besides the bias found for all cases, the rate at which the semivariograms reach their maximum is clearly different among the cases: both MM5 and InSAR show that 12 February is the one having the smallest rate (Fig. 14, black lines), whereas 3 February is the one with the highest rate (Fig. 14, cyan lines). Moreover a good agreement between MM5 and InSAR is found: at small scale for 12 February and at all scales for 3 February (Fig. 13). This behaviour supports the conclusion inferred by comparing MM5 and InSAR maps (Figs. 5, 7, 9, and 11), which clearly shows that MM5 simulations miss some feature at small spatial scales respect to InSAR observations and confirms the good agreement between MM5 and SAR for 3 and 12 February.

In summary, though the high resolution $(1 \mathrm{~km})$ MM5 simulations do not exactly reproduce the spatial structure of integrated water vapour measured by InSAR at about $100 \mathrm{~m}$ resolution, the semivariograms allow to assess the MM5 ability to reproduce the signal structure of the InSAR observations and to describe their spatial correlation features in some of the cases studied (for instance 3 February 1994).

\section{Conclusions}

This study investigates the MM5 ability in reconstructing high resolution water vapour field over the urban area of Rome and its surroundings. Water vapour is one of the most important atmospheric components but still one of the least understood; from the modelling point of view, uncertainties on the initial conditions of this field represent a big source of error even on the short term forecast. At high resolution, the errors are even larger. The InSAR integrated water vapour data, inferred from a long series of radar images processed using the PS technique, would probably largely reduce this error because of the high spatial resolution. For this purpose the water vapour mixing ratio should be retrieved from the InSAR data. The retrieval process requires two preliminary steps: 1) to isolate the atmospheric contribution to the interferograms from the eventual ground motion signals; 2) to convert residual phase delay difference (APS) into water vapour. On the other hand, the wet component of the signal delay must be evaluated to correct InSAR interferograms when the long series on a stable terrain is not available. The water vapour fields produced by a high resolution meteorological model can be used to this purpose, even though its ability to reproduce reliable atmospheric scenarios has to be evaluated first.

Most of the cases analyzed in this study show a good agreement between the MM5 integrated water vapour content and the InSAR one. The results suggest an improvement in the IWV structure representation if a high resolution model is used, even if a time delay or a misplacement of the water vapour distribution is found for a few cases. A good agreement between MM5 at low resolution and InSAR data in term of differential interferograms was also found by Foster et al. (2006), beside for an over/underestimation and displacement of the maxima/minima values. The comparison between MM5 and both soundings and surface stations infers an overall good model ability in reproducing several meteorological parameters at the chosen model resolution. Based on the semivariograms results, we can state that the model generally produces coherent water vapour field respect to radar measurements and it is able to capture its main spatial features especially at low resolution. For two cases this is true at high resolution too. Moreover, the semivariograms analysis suggests the possibility to deduce from the model useful statistical constraints to be applied to interferograms process for reconstructing wet delay component, even when the model does not reduce the variance of satellite images (i.e. where a bias exists between model and InSAR variograms).

In conclusion, this study contributes to single out the value of a high resolution model in reproducing the fine meteorological structures mostly due to the local dynamics, though more efforts must be devoted to correct time delay errors possibly using data assimilation. Therefore, the work contributes to understand the potentiality of using the simulated high resolution water vapour fields for removing the atmospheric contribution in the InSAR signal. Moreover, it points out the possibility to exploit long series of interferometric data to provide the meteorological information on water vapour useful for data assimilation purposes and thus weather forecast improvement. 
Acknowledgements. This research is supported by METAWAVE ESA project Contract No. 21207/07/NL/HE. NCAR is acknowledged for MM5. CETEMPS is acknowledged for computing time availability.

Edited by: S. Michaelides, K. Savvidou, and F. Tymvios Reviewed by: two anonymous referees

\section{References}

Collier, C. G.: The impact of urban areas on weather, Q. J. Roy. Meteor. Soc., 132, 1-25, 2006.

Dandou, A., Tombrou, M., Akylas, E., Soulakellis, N., and Bossioli, E.: Development and evaluation of an urban parameterization scheme in the Penn State/NCAR Mesoscale Model (MM5), J. Geophys. Res., 110, D10102, doi:10.1029/2004JD005192, 2005.

Davis, J. L., Herring, L. T. A., Shapiro, I. I., Rogers, A. E., and Elgered, G.: Geodesy by radio interferometry: Effects of atmospheric modelling errors on estimates of baseline length, Radio Sci., 20, 1593-1607, 1985.

Dudhia, J.: A nonhydrostatic version of the Penn State-NCAR Mesoscale Model: validation tests and simulation of an atlantic cyclone and cold front, Mon. Weather Rev., 129, 1493-1513, 1993.

Ferretti, A., Prati, C., and Rocca, F.: Permanent Scatterers in SAR Interferometry, IEEE TGARS, 39(1), 8-20, doi:10.1109/36.898661, 2001.

Ferretti, A., Colesanti, C., Perissin, D., Prati, C., and Rocca, F.: Evaluating the effect of the observation time on the distibution of SAR Permanent Scatterers, Proceedings of FRINGE03, Frascati, Italy, December 2003a.

Ferretti, R., Mastrantonio, G., Argentini, S., Santoleri, L., and Viola, A.: A model-aided investigation of winter thermally driven circulation in the Italian Tyrrhenian coast for a case study, J. Geophys. Res., 108(D24), 4777-4792, 2003 b.

Ferretti, R. and Raffaele, F.: Impact of the urban modification on the circulation of the Milan urban area. Part I: Model simulations and observations, Q. J. Roy. Meteor. Soc., submitted, 2009.

Foster, J., Brooks, B., Cherubini, T., Shacat, C., Businger, S., and Werner, C. L.: Mitigating atmospheric noise for InSAR using a high resolution weather model, Geophys. Res. Lett., 33, L16304, doi:10.1029/2006GL026781, 2006.
Hanssen, R. F., Weckwerth, T. M., Zebker, H. A., and Klees, R.: High-resolution water vapour mapping from interferometric radar measurements, Science, 283, 1297-1299, 1999.

Hong, S.-Y. and Pan, H.-L.: Nonlocal boundary layer vertical diffusion in medium-range forecast model, Mon. Weather Rev., 124, 2322-2339, 1996.

Kain, J. S. and Fritsch, J. M.: Convective parameterization for mesoscale models: the Kain-Fritsch scheme, Meteor. Mon., 24(46), 165-170, 1993.

Kain, J. S.: The Kain-Fritsch convective parameterization: an update, J. Appl. Meteorol., 43(1), 170-181, 2004.

Kuo, Y.-H., Guo, Y.-R., and Westwater, E.: Assimilation of precipitable water measurement into a mesoscale numerical model, Mon. Weather Rev., 121, 1215-1238, 1993.

Kuo, Y.-H., Zou, X., and Guo, Y.-R.: Variational assimilation of precipitable water using a nonhydrostatic mesoscale adjoint model. Part I: Moisture retrieval and sensitivity experiments, Mon. Weather Rev., 124, 122-147, 1996.

Onn, F. and Zebker, H. A.: Correction for interferometric synthetic aperture radar atmospheric phase artifacts using time series of zenith wet delay observations from a GPS network, J. Geophys. Res., 111, B09102, doi:10.1029/2005JB004012, 2006.

Reisner, J., Rasmussen, R., and Bruintjes, R.: Explicit forecasting of supercooled liquid water in winter storms using the MM5 mesoscale model, Q. J. Roy. Meteor. Soc., 124, 1071-1107, 1998.

Rotunno, R. and Ferretti, R.: Mechanisms of intense Alpine rainfall, J. Atmos. Sci., 58, 1732-1749, 2001.

Rotunno, R. and Ferretti, R.: Orographyc analysis of rainfall in MAP cases IOP2B and IOP8, Q. J. Roy. Meteor. Soc., 129B, 373-390, 2003.

Solheim, F. S., Vivekanandan, J., Ware, R., and Rocken, C.: Propagation delays induced in GPS signals by dry air, water vapour, hydrometeors, and other particulates, J. Geophys. Res., 104(D8), 9663-9670, 1999.

Stephens, G. L.: The parametrization of radiation for numerical Weather prediction and climate models, Mon. Weather Rev., 112, 826-867, 1984.

Webley, P. W., Bingley, R. M., Dodson, A. H., Wadge, G., Waugh, S. J., and James, I. N.: Atmospheric water vapour correction to InSAR surface motion measurements on mountains: results from a dense GPS network on Mount Etna, Phys. Chem. Earth 27, 363-370, 2002. 